\title{
Genetic study of congenital heart defects in Northern Ireland (1974-1978)
}

\author{
E Jennifer Hanna, Norman C Nevin, John Nelson
}

\begin{abstract}
Congenital heart defects are a major congenital abnormality and are assuming increasing importance. A study was undertaken to estimate the incidence of congenital heart defects in Northern Ireland over a five year period (1974-1978), to determine the age at diagnosis and to assess the risk of recurrence in sibs. An incidence rate of $7 \cdot 3$ per 1000 total births was found. This reduced to $3 \cdot 1$ per 1000 total births if only invasive methods of diagnosis (catheter studies, surgery, or necropsy) were considered. The overall risk of recurrence for sibs (excluding index patients with chromosomal abnormalities and syndromes) was $3 \cdot 1 \%$. In addition, excluding families with an affected parent and child gave a recurrence risk of $2 \cdot 6 \%$.

By 6 weeks of age $63 \%$ of index patients had been diagnosed and this figure had risen to $88 \%$ by 1 year. This has important implications for studies which include only congenital heart defects diagnosed in the first year of life.
\end{abstract}

Of 388 patients with a congenital heart defect confirmed by invasive criteria, $96(24.7 \%)$ were found to have an extracardiac abnormality (ECA). Excluding those with epilepsy or mental handicap as the sole ECA left $91(23.5 \%)$ with an ECA. This highlights the importance of looking for other abnormalities in a child with a congenital heart defect.

The 388 index patients had 952 sibs of whom $72(7.6 \%)$ had an ECA. Excluding those with minor abnormalities (inguinal hernias, undescended testes) as the sole ECA left $62(6.5 \%)$ with a major ECA. In addition, excluding those with epilepsy or mental handicap as the sole ECA left 51 $(5 \cdot 4 \%)$ with a major ECA. Since parents are often reassured after the birth of a child with a congenital heart defect that their risk of having a child with a noncardiac abnormality is no greater than the general population this finding has important implications for genetic counselling.

( $(\mathcal{H}$ Med Genet 1994;31:858-863)

Many studies ${ }^{1-10}$ have looked at the incidence of congenital heart defects (CHD) using different methods of ascertainment and differing follow up periods. Some studies ${ }^{68-10}$ have looked at the incidence of congenital heart defects in the first year of life and, with the advent of echocardiography, have been able to diagnose lesions more accurately by non-invasive means.

The aim of this study, which allowed a follow up period of 6 to 10 years (1979-1984), was to obtain an accurate estimate of the incidence of CHD in Northern Ireland. It included the total live- and stillbirth population over a five year period (1974-1978) but unfortunately echocardiography was not available for all patients during the period of study.

Previous studies ${ }^{3611-14}$ have shown a recurrence risk in sibs varying from $1 \cdot 4 \%$ to $3 \cdot 4 \%$. To ascertain the recurrence risk in Northern Ireland, selected families identified by the incidence study were examined in greater detail. In addition it was decided to look at the age at diagnosis of the congenital heart defect to see what proportion escaped detection in the first year of life.

Many studies ${ }^{1615-20}$ have shown that the prevalence of extracardiac abnormalities (ECA) in patients with congenital heart defects is much higher than in the general population, varying from $9 \%$ to $30 \%$. In addition, several investigators have examined the prevalence of ECA associated with specific congenital heart defects. Campbell ${ }^{16}$ found the prevalence varied from $5 \%$ in index patients with atrial septal defect (ASD) to $13 \%$ in patients with coarctation of the aorta $(\mathrm{CoA})$ and pulmonary valve stenosis (PVS). Lamy et $a l^{17}$ reported a prevalence of $7 \cdot 4 \%$ associated with CoA rising to $26.8 \%$ with ASD. Boon and Roberts ${ }^{21}$ found a prevalence of $7 \%$ in 100 cases of CoA whereas Boon et a ${ }^{22}$ found a $16 \%$ prevalence of ECA in 100 cases of tetralogy of Fallot (TF). Williamson ${ }^{23}$ found a prevalence of $8.2 \%$ of ECA in 135 cases of ASD secundum.

Some studies included only "major" abnormalities, while others included "minor" abnormalities, for example, inguinal hernia, undescended testis. Some were restricted to congenital malformations while others also included epilepsy and mental handicap. Overall, it appeared that the majority of ECA were related to the musculoskeletal, genitourinary, or gastrointestinal systems. We were interested to ascertain if similar associations were found in our population.

\section{Subjects and methods}

Multiple independent sources of ascertainment of infants with congenital heart defects were available in Northern Ireland during the study period. These included hospital cardiology records, the Registrar General's Congenital Malformation Notification, the Child Health System, necropsy records, death certificates, records of the Department of Medical Genetics, and neonatal paediatric records. 
Table 1 Congenital heart defects: source of ascertainment (total no of patients ascertained $=972$ )

\begin{tabular}{|c|c|c|c|c|c|c|c|}
\hline $1974-1978$ & $\begin{array}{l}\text { Cardiologist } \\
\text { records }\end{array}$ & $\begin{array}{l}\text { Medical } \\
\text { genetic } \\
\text { records }\end{array}$ & $\begin{array}{l}\text { Registrar } \\
\text { General }\end{array}$ & $\begin{array}{l}\text { Child } \\
\text { health } \\
\text { system }\end{array}$ & $\begin{array}{l}\text { Necropsy } \\
\text { records }\end{array}$ & $\begin{array}{l}\text { Death } \\
\text { certificates }\end{array}$ & $\begin{array}{l}\text { Neonatal } \\
\text { records }\end{array}$ \\
\hline $\begin{array}{l}\text { Total ascertained } \\
\text { Solely ascertained }\end{array}$ & $\begin{array}{l}545 \\
(56 \cdot 1 \%) \\
298 \\
(30 \cdot 7 \%)\end{array}$ & $\begin{array}{l}120 \\
(12 \cdot 3 \%) \\
12 \\
(1 \cdot 2 \%)\end{array}$ & $\begin{array}{l}303 \\
(31 \cdot 2 \%) \\
32 \\
(3 \cdot 3 \%)\end{array}$ & $\begin{array}{c}146 \\
(15 \cdot 0 \%) \\
1 \\
(0 \cdot 1 \%)\end{array}$ & $\begin{array}{l}187 \\
(19 \cdot 2 \%) \\
25 \\
(2 \cdot 6 \%)\end{array}$ & $\begin{array}{l}234 \\
(24 \cdot 1 \%) \\
37 \\
(3 \cdot 8 \%)\end{array}$ & $\begin{array}{l}261 \\
(26.9 \%) \\
116 \\
(11.9 \%)\end{array}$ \\
\hline
\end{tabular}

At the time of the study there were two cardiologists in the province who dealt with the majority of paediatric referrals including all children who progressed to catheterisation or cardiac surgery. The Registrar General's Congenital Malformation Notification is a voluntary system for the notification of congenital malformations in Northern Ireland and the Child Health System is a register of all births in Northern Ireland. ${ }^{24}$ Each record, in addition to identification data, also includes information on a maximum of four congenital malformations. During the study period (1974-1978) records of necropsies, which were carried out mainly in the Belfast and Londonderry hospitals, were examined. Copies of all death certificates and stillbirth records were examined and details extracted on all children born between 1974 1978 inclusive who died with a congenital heart defect. The diagnostic index of the Department of Medical Genetics and neonatal records for all births in the three major maternity units in Belfast were also examined. Stillborn or premature babies with a patent ductus arteriosus or babies whose ductus closed spontaneously within two weeks of birth were not included in the study.

To estimate the recurrence risk in sibs, the family history of children with a congenital heart defect was documented. It was decided to investigate only the families of children in whom the diagnosis had been confirmed by catheter studies, surgery, or necropsy since echocardiography was not available for all patients during the period of study and was only becoming established during our follow up period (1979-1984).

During the period (1974-1978 inclusive), 972 children with a congenital heart defect were ascertained. Of these, 417 had the diagnosis confirmed by invasive criteria (catheter studies, surgery, or necropsy). In this group 388 families $(93 \%)$ were traced, the parents were interviewed, and a detailed pedigree obtained. ${ }^{25}$ Efforts were made to obtain all relevant hospital notes.

\section{Results}

INCIDENCE

During the five year study period (1974-1978), 972 patients with a congenital heart defect were ascertained. Table 1 shows the distribution by source of ascertainment. The number of infants with congenital heart defects and the incidence for each year are shown in table 2 . The incidence ranged from 6.0 per 1000 total births in 1975 to 8.6 per 1000 total births in 1977 , with a mean for the study period of $7 \cdot 3$ per 1000 total births. If only those with a diagnosis confirmed by invasive methods (catheterisation, cardiac surgery, necropsy) are considered (417 patients) this gave an incidence rate of $3 \cdot 15$ per 1000 total births.

\section{RECURRENCE RISK IN SIBS}

Of the 417 index patients who had the diagnosis confirmed by catheter studies, surgery, or necropsy, $388(93 \%)$ were traced. Only 29 families $(7.0 \%)$ could not be contacted. Of these 24 could not be traced, four had moved from Northern Ireland, and the remaining child was in long term foster care and his natural mother was unavailable. The 388 index patients had a total of 952 sibs of whom $28(2.9 \%)$ had a congenital heart defect. There were also 32 half sibs, of whom one $(3 \cdot 1 \%)$ had a congenital heart defect. A chromosomal abnormality was identified in 12 of the index patients. When these patients were excluded this left 376 index patients with a CHD confirmed by catheter studies, surgery, or necropsy who had been traced. When' the sibs of the 12 index patients with a chromosomal abnormality were excluded, this left 921 sibs of whom $28(3.0 \%)$ had a congenital heart defect.

Seven of the index patients had syndromes which were known to be associated with congenital heart defects (three with Noonan, one with Holt-Oram, one with Klippel-Feil, one with fetal hydantoin, and one with Goldenhar (oculoauriculovertebral) syndrome). When these patients were excluded this left 369 index patients who had 909 sibs of whom $28(3 \cdot 1 \%)$ had a congenital heart defect.

There were 11 index patients who had a parent with a documented congenital heart defect (table 3). When these index patients were excluded this left 358 index patients who had 896 sibs of whom $23(2 \cdot 6 \%)$ had a congenital heart defect. Within the families with an affected parent and child, the recurrence risk was $38 \%$ (five recurrences out of 13 sibs).

\section{AGE AT DIAGNOSIS}

Table 4 shows the age at diagnosis. Under six weeks $62.9 \%$ of children with a congenital heart defect were detected, and by one year the figure had risen to $87.9 \%$. Thus, $12.1 \%$ remained undetected at one year. Of those 47 cases which remained undiagnosed at one year, 17 had 
Table 3 Congenital heart defects in parents of index patients

\begin{tabular}{llll}
\hline Sex & Parent CHD & Sex & Index patient CHD \\
\hline F & VSD & F & CoA \\
F & VSD & M & VSD \\
F & VSD & M & VSD \\
F & PDA & F & PDA \\
F & PDA & F & PDA \\
F & PDA & F & PDA \\
F & TF & M & TF \\
F & AR & M & PS \\
M & HOCM & F & PS/VSD \\
M & ASD & F & ASD \\
M & SVAS & F & SVAS \\
\hline
\end{tabular}

VSD = ventricular septal defect; CoA=coarctation of aorta; PDA = patent ductus arteriosus; $T F=$ tetralogy of Fallot $\mathrm{AR}=$ aortic regurgitation; $\mathrm{PS}=$ pulmonary stenosis; HOCM = hypertrophic obstructive cardiomyopathy; $A S D=$ atrial septal

Table 4 Age at diagnosis of congenital heart defect (total no of index patients $=388$ )

\begin{tabular}{lll}
\hline Age & No diagnosed & Percentage of total \\
\hline Less than 1 wk & 171 & $44 \cdot 1$ \\
1-6 wk & 73 & $18 \cdot 8$ \\
6 wk-3 mth & 40 & $10 \cdot 3$ \\
3-6 mth & 32 & $8 \cdot 2$ \\
6-12 mth & 25 & $6 \cdot 4$ \\
1-2 y & 15 & $3 \cdot 9$ \\
$2-3 \mathrm{y}$ & 15 & $3 \cdot 9$ \\
3-4 y & 6 & $1 \cdot 5$ \\
$4-5 \mathrm{y}$ & 6 & $1 \cdot 5$ \\
$5-6 \mathrm{y}$ & 4 & $1 \cdot 0$ \\
$6-7 \mathrm{y}$ & 1 & $0 \cdot 3$ \\
\hline
\end{tabular}

Table 5 Extracardiac abnormalities in 368 index patients (excluding chromosomal abnormalities and syndromes)

\begin{tabular}{lll}
\hline System involved & $\begin{array}{l}\text { No of index patients } \\
\text { affected }\end{array}$ & $\begin{array}{l}\text { Percentage of total } \\
\text { index patients }\end{array}$ \\
\hline Gastrointestinal & 33 & $9 \cdot 0$ \\
Musculoskeletal & 22 & $6 \cdot 0$ \\
Urinary & 20 & $5 \cdot 4$ \\
Eye and ear & 14 & $3 \cdot 8$ \\
CNS & 11 & $3 \cdot 0$ \\
CNS (excl epilepsy and mental handicap) & 6 & $1 \cdot 6$ \\
Immune-haematological & 6 & $1 \cdot 6$ \\
Endocrine & 3 & $0 \cdot 8$ \\
Reproductive & 1 & $0 \cdot 3$ \\
Other & 3 & $0 \cdot 8$ \\
\hline
\end{tabular}

Table 6 Extracardiac abnormalities in 388 index patients associated with specific congenital heart defects

\begin{tabular}{llll}
\hline Congenital heart defect & $\begin{array}{l}\text { No of index } \\
\text { patients }\end{array}$ & $\begin{array}{l}\text { No of index patients with } \\
\text { extracardiac abnormalities }\end{array}$ & Percentage \\
\hline VSD & 68 & 20 & $29 \cdot 4$ \\
PDA & 41 & 10 & $24 \cdot 4$ \\
TGV & 35 & 5 & $14 \cdot 3$ \\
CoA & 30 & 5 & $16 \cdot 7$ \\
TF & 26 & 4 & $15 \cdot 4$ \\
ASD & 24 & 4 & $16 \cdot 7$ \\
Tr Art & 18 & 5 & $27 \cdot 8$ \\
PS & 17 & 4 & $23 \cdot 5$ \\
AVC & 10 & 5 & $30 \cdot 0$ \\
Multiple & 91 & 30 & $14 \cdot 0$ \\
Others & 28 & 4 & \\
\hline
\end{tabular}

VSD = ventricular septal defect; PDA $=$ patent ductus arteriosus; $T G V=$ transposition great vessels; $\mathrm{CoA}=$ coarctation of aorta; $\mathrm{TF}=$ tetralogy of Fallot; $\mathrm{ASD}=$ atrial septal defect Tr Art = truncus arteriosus; PS = pulmonary stenosis; AVC = atrioventricular canal defect

patent ductus arteriosus, six had ventricular septal defect, six had atrial septal defect, six had multiple congenital heart defects, five had coarctation of the aorta, and seven had other specific defects including one with truncus arteriosus type IV.

\section{EXTRACARDIAC ABNORMALITIES IN INDEX} PATIENTS

Of the 388 index patients with a congenital heart defect confirmed by invasive criteria who were traced, $96(24.7 \%)$ had extracardiac abnormalities (ECA). Three of them had epilepsy and two had mental handicap as the sole abnormality. Excluding these patients, 91 $(23.5 \%)$ had ECA. A chromosomal abnormality was found in 12 patients $(3 \cdot 1 \%)$. This figure is low owing to fewer patients with a chromosomal abnormality (in particular Down syndrome) having invasive cardiac investigations which was the criteria for inclusion in this part of the study. Eight patients $(2 \cdot 1 \%)$ were known to have a syndrome. Three had Noonan syndrome, one had Holt-Oram syndrome, one had Klippel-Feil syndrome, one had testicular feminisation syndrome, one had fetal hydantoin syndrome, and one had Goldenhar (oculoauriculovertebral) syndrome. Also excluding index patients with chromosomal abnormalities and syndromes left 71 $(18.3 \%)$ who had ECA.

Several index patients had more than one ECA and table 5 shows the percentage accounted for by each system after patients with chromosomal abnormalities and "syndromes" have been excluded leaving 368 index patients. The commonest system affected was the gastrointestinal followed by the musculoskeletal and urinary systems. Of the 33 patients with a gastrointestinal ECA, nine had oesophageal atresia \pm tracheo-oesophageal fistula, five had situs inversus, five had cleft palate \pm cleft lip, five had inguinal hernia, three had imperforate anus, and six had other abnormalities.

Table 6 shows the extracardiac abnormalities in association with specific congenital heart defects in the 388 index patients (patients with chromosomal abnormalities and known syndromes included). Half the patients with $\mathrm{A}-\mathrm{V}$ (AVC) canal defect had an ECA (Down syndrome in four of the five cases with an ECA), and more than a quarter of index patients with multiple heart defects, ventricular septal defect (VSD), or truncus arteriosus ( $\mathrm{Tr}$ Art) had ECA. Between 20 and $25 \%$ of patients with patent ductus arteriosus (PDA) or pulmonary stenosis (PS) had ECA, and between 10 and $20 \%$ of patients with atrial septal defect (ASD), coarctation of the aorta $(\mathrm{CoA})$, tetralogy of Fallot (TF), or transposition of great vessels (TV) had ECA.

Of the five index patients with $\operatorname{Tr}$ Art who had an ECA, one had four toes on the right foot and three on the left foot, one had a bifid big toe, and a third had absence of the left thumb and radius. Two of the five patients had bilateral iris colobomata. No other association was noted between specific heart defects and specific types of ECA.

\section{EXTRACARDIAC ABNORMALITIES IN SIBS}

Of the 952 sibs, $72(7.6 \%)$ had one or more ECA. When minor abnormalities such as inguinal hernia or undescended testes were excluded, this left $62(6.5 \%)$ with a major ECA. Of these, eight had mental handicap and three others had epilepsy as the sole ECA. When these were excluded, $51(5 \cdot 4 \%)$ had a major ECA.

Table 7 shows the distribution of ECA 
Table 7 Extracardiac abnormalities in 952 sibs of index patients by system involved

\begin{tabular}{lll}
\hline System & No of affected sibs & Percentage total \\
\hline Central nervous & 28 & $2 \cdot 9$ \\
Gastrointestinal & 17 & $1 \cdot 8$ \\
Musculoskeletal & 11 & $1 \cdot 2$ \\
Urinary & 6 & $0 \cdot 6$ \\
Eye & 5 & $0 \cdot 5$ \\
Immune-haematological & 4 & $0 \cdot 4$ \\
Reproductive & 4 & $0 \cdot 4$ \\
Chromosomal & 3 & $0 \cdot 3$ \\
Other & 4 & $0 \cdot 4$ \\
\hline
\end{tabular}

between the various systems in the 952 sibs. Abnormalities in the CNS included 12 patients with mental handicap (1.3\% of total sibs) and three with epilepsy. There were also 10 cases of neural tube defect or hydrocephalus or both, thus affecting $1 \cdot 1 \%$ of all sibs.

Table 8 shows the percentage of ECA found in sibs of patients with specific congenital heart defects. This varies from $4.3 \%$ to $11 \cdot 4 \%$. Truncus arteriosus had the highest rate $(11 \cdot 4 \%)$ but the majority of these ECA were minor. PDA had the highest overall rate for major ECA in sibs.

There were five sibs of index patients with pulmonary stenosis who had ECA. It is interesting that in two cases the abnormality was a large cavernous haemangioma affecting the forehead and shoulder in one, and the right knee in the other. No other associations were noted between specific types of congenital heart defect in the index patients and specific types of ECA in their sibs.

The $28 \mathrm{CHD}$ recurrences in sibs occurred in the families of 27 index cases. Three of these index cases had ECA and six of the 28 recurrences also had ECA. Of their remaining sibs, nine had an ECA without a CHD and 53 were apparently normal although five died in infancy from undocumented causes.

\section{Discussion}

The incidence rate of $7 \cdot 3$ per 1000 total births for the five year study period is comparable to surveys from other countries ${ }^{2-5}$ and is in good agreement with the rate of $7 \cdot 6$ per 1000 births obtained by Stoll et $a l^{6}$ from France and the rate of $7 \cdot 2$ per 1000 births obtained by Bower and Ramsay ${ }^{7}$ from data from the Western Australian Birth Defects Registry.

It is, however, higher than that found when only cases diagnosed in the first year of life by echocardiography, catheterisation, surgery, or necropsy are included. Grabitz et $a l^{8}$ found an incidence of 5.54 per 1000 livebirths in the first year of life using these diagnostic criteria and Ferencz et al ${ }^{9}$ reported an incidence of 3.7 per 1000 livebirths in the first year of life. However, using clinical criteria, Grabitz et al obtained an incidence of 6.58 per 1000 livebirths.

If only those cases confirmed by invasive means are considered, that is, catheterisation, surgery, or necropsy, our rate of $3 \cdot 15$ per 1000 total births is higher than that found in other studies using similar invasive criteria $(2.4$ per 1000 livebirths by Ferencz et $a l^{9}$ and $2 \cdot 20$ per 1000 livebirths by Fyler ${ }^{10}$ ). These studies only considered livebirths and diagnosis made in the first year of life, so it is not surprising that the incidence rates found were lower. However, Grabitz et al, ${ }^{8}$ who also studied livebirths with follow up in the first year of life, found an incidence of 3.36 per 1000 livebirths using invasive criteria.

Our figure of 7.3 per 1000 total births is still likely to be an underestimate for several reasons. Firstly, there will be some children whose congenital heart defect remained undetected. For example, one of the authors (EJH) diagnosed an unsuspected ASD secundum requiring cardiac surgery in a 5 year old boy during the course of this study. Secondly, there will be children attending their general practitioner or paediatrician because of a cardiac murmur who have not been notified to any data recording system. Children with patent ductus arteriosus or ventricular septal defect which close spontaneously are likely to fall into this category. Thirdly, the majority of stillborn infants delivered in major teaching centres had a necropsy, but this service was not so readily available in other areas of Northern Ireland.

The paediatric cardiologist was the most important source of ascertainment. Of the total 972 cases, $545(56 \cdot 1 \%)$ were ascertained from the records of the cardiologists, $298(30.7 \%)$ being ascertained solely from this source. Interestingly 116 cases $(11.9 \%)$ were ascertained solely by the neonatal recording system and 25 cases $(2 \cdot 6 \%)$ were diagnosed only at necropsy. Most cases ascertained by examination of neonatal records had also been assessed by a paediatric cardiologist but were not always entered in the cardiologist's records.

The overall recurrence rate among sibs of $3.1 \%$ (excluding index patients with chromoso-

Table 8 Extracardiac abnormalities in 952 sibs of index patients: variation with specific heart defects in the index patient

\begin{tabular}{lllll}
\hline $\begin{array}{l}\text { Congenital heart defect } \\
\text { in index patient }\end{array}$ & $\begin{array}{l}\text { No of } \\
\text { sibs }\end{array}$ & $\begin{array}{l}\text { Percentage of sibs } \\
\text { with ECA }\end{array}$ & $\begin{array}{l}\text { Percentage sibs } \\
\text { with major ECA }\end{array}$ & $\begin{array}{l}\text { Percentage sibs with } \\
\text { major ECA excl mental } \\
\text { handicap and epilepsy }\end{array}$ \\
\hline VSD & 141 & $7 \cdot 1$ & $5 \cdot 7$ & $4 \cdot 3$ \\
PDA & 89 & $10 \cdot 1$ & $10 \cdot 1$ & $9 \cdot 0$ \\
ASD & 72 & $8 \cdot 3$ & $8 \cdot 3$ & $2 \cdot 8$ \\
TF & 60 & $8 \cdot 3$ & $8 \cdot 3$ & $6 \cdot 7$ \\
TGV & 106 & $9 \cdot 4$ & $6 \cdot 6$ & $6 \cdot 6$ \\
PoA & 75 & $6 \cdot 7$ & $6 \cdot 7$ & $5 \cdot 3$ \\
Pr Art & 57 & $8 \cdot 8$ & $8 \cdot 8$ & $5 \cdot 3$ \\
Others & 35 & $11 \cdot 4$ & $5 \cdot 7$ & $2 \cdot 9$ \\
Multiple & 93 & $4 \cdot 3$ & $3 \cdot 2$ & $3 \cdot 2$ \\
Total & 224 & $6 \cdot 7$ & $6 \cdot 3$ & $5 \cdot 8$ \\
\hline
\end{tabular}

$\mathrm{VSD}=$ ventricular septal defect; $\mathrm{PDA}=$ patent ductus arteriosus; $\mathrm{ASD}=$ atrial septal defect; $\mathrm{TF}=$ tetralogy of Fallot; TGV $=$ transposition great vessels; $\mathrm{CoA}=$ coarctation of aorta; $\mathrm{PS}=$ pulmonary stenosis; $\mathrm{Tr}$ art $=$ truncus arteriosus 
mal abnormalities and syndromes) is comparable with that of other studies. ${ }^{34611-14}$

While the numbers in this study were too small to estimate accurately recurrence risks in sibs for specific congenital heart defects, a number of interesting families were ascertained (table 3). For many years it has been suggested that isolated ASD may rarely exhibit autosomal dominant inheritance. ${ }^{26}$ In our study a family was identified in which a father in his early thirties had two daughters with ASD secundum. After the diagnosis was made in both girls the father was found to have a similar lesion but unfortunately died undergoing corrective cardiac surgery.

Supravalvular aortic stenosis (SVAS) is well recognised as segregating in an autosomal dominant manner in some families. ${ }^{27} \mathrm{We}$ ascertained a family in which a number of persons had SVAS but many of their offspring had peripheral pulmonary artery stenosis (PPAS) in addition to SVAS while other offspring had SVAS or PPAS but not both. Male to male transmission was present in this family in which 17 subjects were affected in four generations.

Similarly, families have been described in which PDA appears to be inherited in an autosomal dominant manner. ${ }^{28} \mathrm{We}$ ascertained two families in which the mother and each of her two children (two daughters in one family and a daughter and son in the other) had a PDA. In a further family a mother and her son both had tetralogy of Fallot and in two other families a mother, son, and daughter in one and a mother and son in the other all had ventricular septal defects. Further families with a parent with a documented congenital heart defect included a mother with aortic regurgitation who had a son with pulmonary stenosis, a mother with a VSD who had a daughter with coarctation of the aorta, and a father with hypertrophic obstructive cardiomyopathy who had a daughter with pulmonary stenosis and a VSD.

It is of interest that the majority of affected parents (eight out of 11) were female (table 3). Nora and Nora $^{29}$ postulated that an important subset of cases, particularly in high risk families, may be better explained by cytoplasmic rather than by multifactorial or mendelian inheritance. However, our study is too small for us to be certain whether the excess of females found in affected parents is of significance or not.

A previous study ${ }^{5}$ in Blackpool (1957-1971) examined the age at diagnosis of patients with a congenital heart defect and found that $74 \%$ were diagnosed before 3 months of age, $82 \%$ before 1 year, and $90 \%$ before 3 years. In our study, $73 \%$ were diagnosed before 3 months of age, $88 \%$ before 1 year, and $96 \%$ before 3 years (table 4). It would thus appear that there has been little improvement in early diagnosis during the time interval between these two studies and even major defects may remain undetected during the first year. This is an important point when considering studies ${ }^{8-10}$ which record only congenital heart defects diagnosed in the first year of life.

Selection of index patients will obviously be an important factor in the estimate of ECA in children with congenital heart defects. In this study only families where the defect had been confirmed by invasive criteria (catheter studies, surgery, or necropsy) were included. This selection criteria meant that less severe defects and chromosomal abnormalities were underrepresented, as these were less likely to have further invasive investigations. Ascertainment of children with multiple abnormalities will also be affected since fewer will have further cardiac investigations but more may have necropsy.

These selection biases makes it difficult to be sure if the figure of $24.7 \%$ of index patients with an ECA is an over- or underestimate. However, it is comparable with that found in most other studies ${ }^{1517-20}$ and is in good agreement with the figure of $25 \cdot 7 \%$ found by Stoll et $a l,{ }^{6}$ who also found that the most frequent ECA were in the gastrointestinal, musculoskeletal, and urinary systems. The $9 \%$ found by Campbell $^{16}$ is probably an underestimate as he included only patients suitable for cardiac surgery. Several studies ${ }^{151920}$ also included a higher proportion of index patients with Down syndrome, and these accounted for 23 to $29 \%$ of their index patients with ECA. Heinonen ${ }^{18}$ and $S \operatorname{cott}^{19}$ also found a signficant number of index patients with other syndromes $(11.9 \%$ and $4.9 \%$ respectively).

Our finding of $24.7 \%$ of index patients with ECA which is approximately 10 times the incidence of major congenital abnormalities in our population ${ }^{30}$ highlights the importance of looking for other abnormalities in a child with a congenital heart defect. However, the numbers in our study were too small to comment meaningfully on the prevalence of ECA associated with specific congenital heart defects.

The incidence of neural tube defects in Northern Ireland for the period 1974-1976 was estimated to be 8.6 per 1000 births $^{24}$ so our finding of $1 \cdot 1 \%$ of sibs with a neural tube defect or hydrocephalus or both may not be significant. Interestingly, Heinonen ${ }^{18}$ found that malformation of the head or spine or both in an older sib was associated with a doubling of the risk of cardiovascular malformation.

After the birth of a child with a congenital heart defect genetic counselling is important. The parents are appraised of the risk of having a further affected child. In addition, they are usually reassured that their risk of having a child with a non-cardiac abnormality is no greater than the general population. For the period 1974-1979 the population incidence of major non-cardiac congenital abnormalities in Northern Ireland extrapolated from data published by Nevin ${ }^{30}$ was estimated to be $1.9 \%$ of total births. Our finding of $6.5 \%$ of sibs with a major ECA has obvious important implications for genetic counselling.

We acknowledge the help and advice given by $\mathrm{Dr} \mathrm{H} \mathrm{C}$ Mulholland, Consultant Paediatric Cardiologist, Royal Belfast Hospital for Sick Children and Dr P Morton, Consultant Cardiologist, Belfast City Hospital. The data in this paper are from an MD thesis submitted to The Queen's University of Belfast by one of the authors $(\mathrm{EJH})$.

1 MacMahon B, McKeown T, Record RG. The incidence and life expectation of children with congenital heart disease. Br Heart F 1953;15:121-9.

2 Campbell M. Incidence of cardiac malformations at birth and 
later, and neonatal mortality. Br Heart f 1973;35:189-200. 3 Heinonen OP. Risk factors for congenital heart disease: prospective study. In: Birth defects: risks and consequences. prospective study. In: Birth defects: risks and

New York: Academic Press, 1976:221-64.
4 Kenna AP, Smithells RW, Fielding DW. Congenital hear disease in Liverpool 1960-1969. $Q \mathcal{F}$ Med 1975;44:17-44.

5 Bound JP, Logan WFWE. Incidence of congenital heart disease in Blackpool 1957-1971. Br Heart $\mathcal{F}$ 1977;39:44550

6 Stoll C, Alembik Y, Roth MP, Dott B, De Geeter B. Risk factors in congenital heart disease. Eur $\mathcal{f}$ Epidemiol 1989;5:382-91.

7 Bower C, Ramsay JM. Congenital heart disease in Western Australia - a ten-year experience. Aust NZ $\mathcal{f}$ Med 1991;21(suppl 2):550.

8 Grabitz RG, Joffres MR, Collins-Nakai RL. Congenita heart disease: incidence in the first year of life. The Albert Heritage Pediatric Cardiology Program. Am J Epidemiol 1988;128:381-8.

9 Ferencz C, Rubin JD, McCarter RJ, et al. Congenital heart disease: prevalence at livebirth. The Baltimore-Wash ington Infant Study. Am $\mathcal{F}$ Epidemiol 1985;121:31-6.

10 Fyler DC. Report of the New England Regional Infant Cardiac Program. Pediatrics 1980;65(suppl):375-461.

11 Anderson RC. Fetal and infant death, twinning and cardiac Anderson RC. Fetal and infant death, twinning and cardiac
malformations in families of 2,000 children with, and 500 without, cardiac defects. Am $\mathcal{f}$ Cardiol 1976;38:218-24.

12 Sanchez-Cascos A. The recurrence risk in congenital heart disease. Eur f Cardiol 1978;7:197-210.

13 Nora JJ, Meyer TC. Familial nature of congenital hear diseases. Pediatrics 1966;37:329-34.

14 Fuhrmann $W$. Research on the etiology of congenital hear defects. Acta Genet (Basel) 1961;11:289-316.

15 Boesen I, Melchior JC, Terslev E, Vendel S. Extracardiac congenital malformations in children with congenital heart disease. Acta Paediatr Scand 1963;146:28-33.

16 Campbell $\mathrm{M}$. Causes of malformations of the heart. $\mathrm{Br} \mathrm{Med} \mathcal{F}$ 1965;2:895-904.
17 Lamy M, de Grouchy J, Schweisguth O. Genetic and nongenetic factors in the etiology of congenital heart disease: a
study of 1188 cases. Am $\mathcal{F}$ Hum Genet $1957 ; 9: 17-41$.

18 Heinonen OP. Risk factors for congenital heart disease: a prospective study. Birth defects: risks and consequences. New York: Academic Press, 1976:221-64.

19 Scott MJ. Congenital malformations in children born in Belfast 1964-1968. MD thesis, The Queen's University of Belfast, 1975.

20 Kenna AP, Smithells RW, Fielding DW. Congenital heart disease in Liverpool 1960-69. $Q \mathcal{F}$ Med 1975;44:17-44.

21 Boon AR, Roberts DF. A family study of coarctation of the aorta. F Med Genet 1976;13:420-33.

22 Boon AR, Farmer MB, Roberts DF. A family study of Fallot's tetralogy. $\mathcal{F}$ Med Genet 1972;9:179-92.

23 Williamson EM. A family study of atrial septal defect. $\mathcal{f} \mathrm{Med}$ Genet 1969;6:255-61.

24 Nevin NC, McDonald JR, Walby AL. A comparison of neural tube defects identified by two independent routine recording systems for congenital malformations in Northern Ireland. Int $\mathcal{F}$ Epidemiol 1978;7:319-21.

25 Hanna EJ. Epidemiological and genetic studies in congenital heart disease. MD thesis, The Queen's University of Belfast, 1985 .

26 Zetterqvist P, Turesson I, Johansson BW, Laurell S, Ohlsson NM. Dominant mode of inheritance in atrial septal son NM. Dominant mode of in

27 Eisenberg R, Young D, Jacobson B, Boito A. Familial supravalvular aortic stenosis. Am $\mathcal{f}$ Dis Child 1964;108:341-7.

28 Burman D. Familial patent ductus arteriosus. Br Heart $\mathfrak{f}$ 1961;23:603-4.

29 Nora JJ, Nora AH. Maternal transmission of congenital heart diseases: new recurrence risk figures and the questions of cytoplasmic inheritance and vulnerability to teratogens. Am $\mathcal{f}$ Cardiol 1987;59:459-63.

30 Nevin NC. The importance of screening for genetic diseases. $R$ Soc Health f 1979;99:37-40. 